\title{
GORRIGENDUM
}

\section{ON THE STABILITY OF LINEAR CANONICAL SYSTEMS WITH PERIODIC COEFFICIENTS}

\author{
Journal of the Australian Mathematical Society 5 (1965), 169-195
}

W. A. COPPEL and A. HOWE

(Received 22 September 1965)

Theorem 9 (p. 183) should read: The indices of any closed curve in $\mathscr{D}$ have the form

$$
n_{+}=h p / s, \quad n_{-}=h q / s,
$$

for some integer $h$, where $s(1 \leqq s \leqq n)$ is the largest number of identical blocks into which the signature $\sigma$ can be partitioned. Moreover, for any integer $h$ there exists a closed curve in $\mathscr{D}$ with these indices.

For example, if $\sigma=(++-++-)$ then $s=2$. The error occurs in the assertion that a closed curve can be continuously transformed into a closed curve of diagonal matrices. In the statement of Theorem 10 the inequality $0 \leqq j<p$ must accordingly be replaced by $0 \leqq j<p / s$. The proof of Theorem 10 remains unaltered. 